\title{
SOMATIC VARIATION IN LOLIUM PERENNE
}

\author{
Y. SHIMAMOTO* and M. D. HAYWARD \\ Welsh Plant Breeding Station, Aberystwyth, Wales
}

Received 4.vii.74

\begin{abstract}
SumMary
An investigation of somatic variation in 10 plants of Lolium perenne, using a two-stage cloning process followed by two further cycles of vegetative propagation, has revealed that persistent differences in tiller number and plant height may arise at the time of the initial cloning. These effects were dependent upon the age of the clone and its past vegetative history. Transmissibility values obtained indicate that up to 77 per cent of the ramet variation for plant height is transmittable over propagation cycles. The implications of these findings with regard to clonal evaluation in forage crop breeding and the maintenance of basic plants of a synthetic variety are briefly considered.
\end{abstract}

\section{INTRODUCTION}

IT has been clearly established that variation may occur between vegetative propagules of a single plant. Such variation may be persistent over further cycles of propagation as in the case of flowering shoots of Hedera helix (Darlington, 1958) or as in plant height of clones of Phleum ambiguum (Palenzona et al., 1973); alternatively they may disappear after a period of time (Libby and Jund, 1962; Hayward and Koerper, 1973). The former effects have been attributed to persistent changes in the plasmon of the individual whilst the latter, or " $\mathrm{C}$ " effects, are generally ascribed to physiological or morphological influences arising from the specific environment in which the original plant developed (Lerner, 1958; Wilcox and Farmer, 1968). In 1965 Breese et al. obtained evidence that intraclonal differences in rates of tillering in Lolium perenne could be enlarged and established by selection over vegetative cycles of reproduction. The effect depended on a number of factors including genotype and age of clone.

The present investigation examines the occurrence of variation arising at the establishment of primary ramets of a series of clones of $L$. perenne and its transmission over several cycles of propagation, with particular reference to age and past history of the clone.

\section{MAterial AND METHODS}

The material consisted of 10 clones of $L$. perenne cultivar S.24. These plants represented a gradient in age and vegetative history. Clones numbers 1 to 4 were of the same genotype, but had been selected for high (numbers 1 and 3) and low (numbers 2 and 4) rates of tiller production and were 4 years old at the commencement of the experiment. Clones 5 and 6 were

* Present address: Laboratory of Industrial Crops, Faculty of Agriculture, Hokkaido University, Sapporo, Japan.

$34 / 2-F$ 
6 months old and clones 7 and 8 were 18 months old. Clones 9 and 10 were established in 1945 and 1947 respectively and were 28 and 26 year old at the start of the experiment and had been maintained by regular vegetative propagation. Eight uniform tillers were taken from each plant to establish primary ramets. After a period of growth five sub-ramets were generated to initiate the first assessment cycle. Three propagation cycles were carried out after growing periods of 100 days for the first cycle and 90 for the second. The five sub-ramets of each generation were established from single tillers of the parental ramets, thus the identity of primary and sub-ramets was maintained throughout the course of the experiment.

The tillers were grown in a completely randomised layout in boxes of John Innes Compost No. 2 in a glasshouse receiving supplementary heat and light which served the dual purpose of maintaining vegetative growth and avoiding floral induction.

The characters studied were tiller number at 5 weeks for the three cycles, and plant height at 7 weeks for the first two cycles only.

The analysis consisted of a mixed model, ramets and sub-ramets being random items and propagation cycles fixed. Where either the sub-ramet and interaction of ramets $\times$ cycles terms were non-significant, the appropriate sums of squares have been accumulated to provide a pooled estimate of error.

\section{Results}

The data obtained for tiller number over the three cycles has been combined and an analysis of variance is shown in table 1 and for plant height over the two cycles at which this character was measured in table 2 .

For tiller number the initial effects of cloning persisted over the duration of the experiment for clones 5, 6, 7 and 8 as measured by the between ramets item (table 1). For plant height differences were maintained for the same clones and in addition for number 10. As expected, there were marked differences between the propagation cycles for all clones except 9 for tiller number, reflecting the different times of year involved. On the other hand, for plant height, which effectively measures leaf-length attained, there was no difference between the cycles except for clones 2, 3, 4 and 10 . The item measuring the interaction of ramets with propagation cycles was significant for three clones, 3, 7 and 10, for tiller number and two, 2 and 3 , for plant height, indicating that the between ramet variation for these clones was not consistent over the cycles. Variation at the sub-ramet level was significant only for clone 7 for both characters, revealing that further segregation occurred at the establishment of the first sub-ramets which was again maintained over the course of the experiment.

The variation arising at the establishment of the first ramets is thus consistent for some clones for both tiller number and plant height. A measure of the transmissibility of this variation may be obtained from the intra-class correlation calculated from the ratio of ramet variance to total variance. Where the between ramets variance is significant, these are presented in tables 1 and 2 . In general, the estimates obtained for plant height are higher than those for tiller number, ranging from 0.149 to 0.883 for the former and from 0.082 to 0.527 for the latter. 


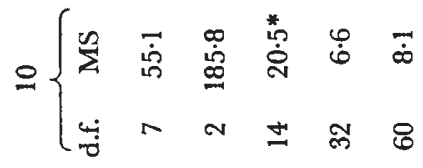

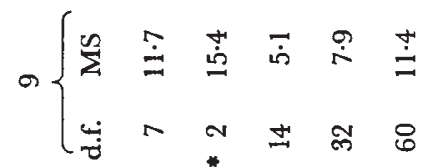

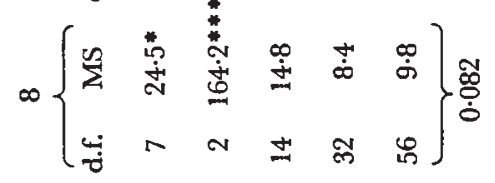

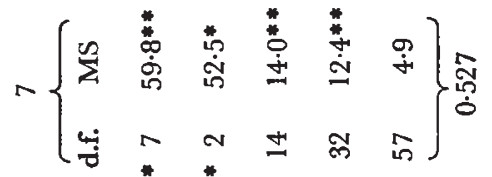

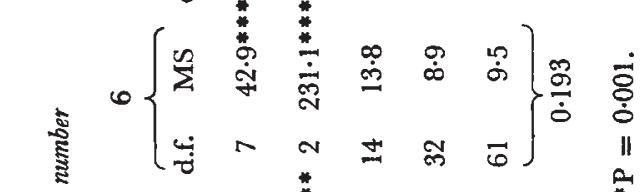

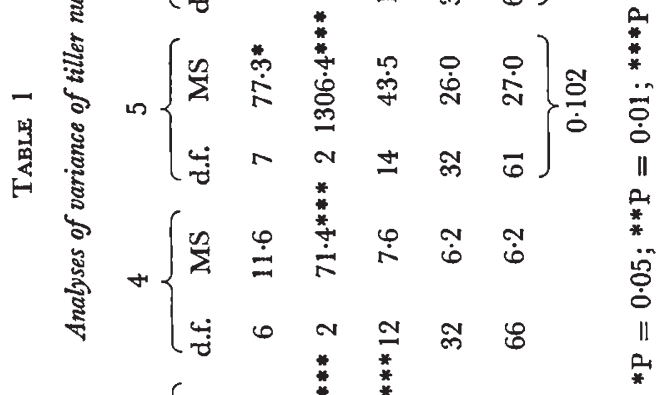

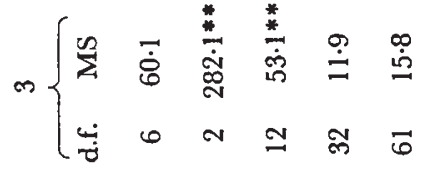

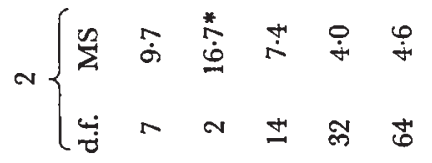

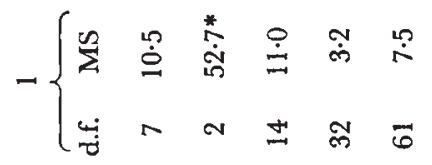

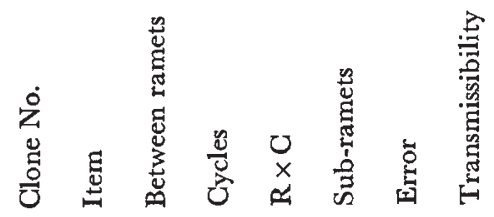




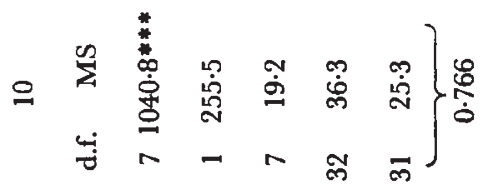

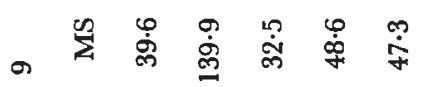

$$
\begin{aligned}
& \text { ษ }-\sim \text { के ल }
\end{aligned}
$$

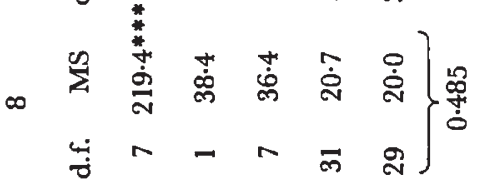

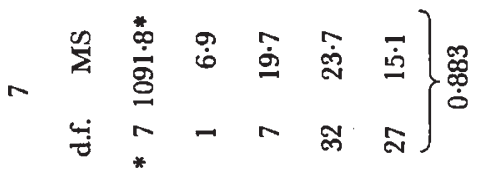

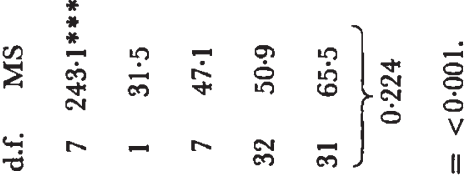

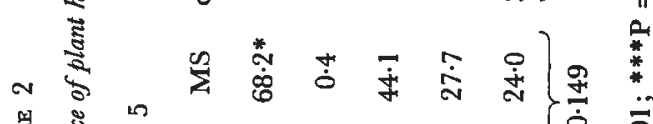

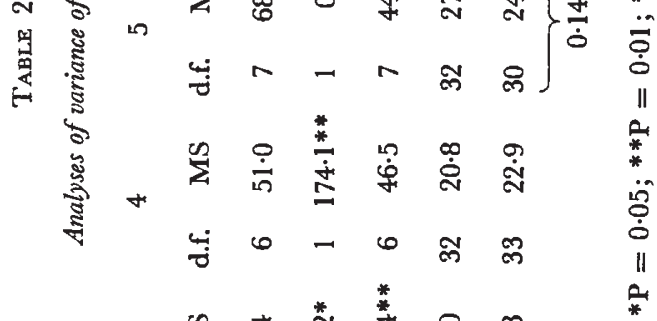

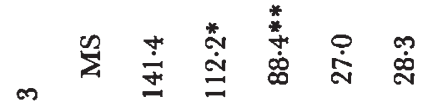

$$
\begin{aligned}
& \text { पु } \omega-\infty \text { ल ले }
\end{aligned}
$$

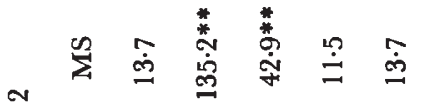

$$
\begin{aligned}
& \text { पुं - ते के }
\end{aligned}
$$

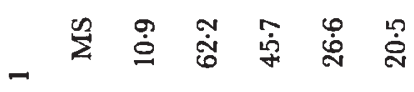

$$
\begin{aligned}
& \text { पु } \rightarrow-\text { ले क }
\end{aligned}
$$

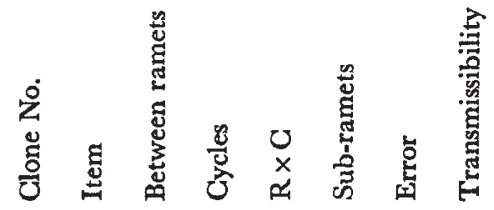




\section{Discussion}

The experiment has clearly shown that for certain clones of $L$. perenne significant variation in tiller number and plant height may arise during the first asexual propagation and persist over further cycles of vegetative reproduction. The origin of this variation may be due to two causes. Firstly the differences between ramets has arisen as a result of physiological inequalities between the initial propagules, the " $\mathrm{C}$ " effects of Libby and Jund (loc. cit.). In this instance, however, such an explanation is unlikely as it would be unusual for such differences to persist over further cycles when grown in a uniform environment. In this respect the present results differ from those of Hayward and Koerper (1973), who established initial differences within clones of $L$. perenne, arising as a result of pre-treatments imposed, which were not maintained after the first vegetative cycle. Alternatively, the variation may be due to cytoplasmic or plasmon differences created during the initial sub-cloning, comparable to the variation utilised by Breese et al. (1965) in their somatic selection experiments in L. perenne.

A significant response to selection for tiller number from within clones was established by Breese et al. (loc. cit.) for clones derived from young seedlings, but not from aged clones. It is of interest to note that in the present experiment the clones which segregated were the young ones, namely 5, 6, 7 and 8 . The remaining clones were either 4 years old and had been subjected to somatic selection, or were some 25 years old and had been maintained by regular vegetative propagation. It would thus appear that the segregation is either age-dependent or dependent upon the past vegetative history of the clones and is comparable to the plasmon variation postulated by Breese et al. (loc. cit.) to account for the response to somatic selection which they obtained. The degree of transmission would appear to be determined by the nuclear genotype, as was the response to somatic selection achieved in the previous experiments referred to. The maximum transmissibility values obtained indicate that some 28 per cent of the ramet variation for tiller number and 77 per cent of that for plant height for clone 7 is transmittable over propagation cycles.

Clonal evaluation is regularly used in the estimation of broad-sense heritabilities in forage crops (Burton and De Vane, 1953; Thomas and Frakes, 1967; Bean, 1972). If a single cycle of propagation is employed, the variation at the ramet level may contribute to the clonal variation and as a consequence overestimate heritability. If, however, the two-stage cloning as proposed by Libby and Jund (1962) is utilised, whereby the ramets at the first cycle are grown in a series of contrasting environments and at the second stage in a uniform environment to allow an accurate measure of " $\mathrm{C}$ " effects to be obtained, their contribution to the clonal variation can be removed in the estimation of heritability. In the present instance the variability demonstrated would not appear to be comparable to the " $\mathrm{C}$ " effects encountered by Libby and Jund (loc. cit.) and Hayward and Koerper (loc. cit.). If the present variation is heritable, as was the plasmon variation associated with population differentiation in L. perenne described by Hayward and Breese (1968), it will contribute to the numerator in the estimation of heritability. Only further breeding tests will elucidate this problem.

One further aspect of the importance of somatic variation in forage crop breeding is in the vegetative maintenance of the basic plants of a 
synthetic variety. It has generally been considered that a progressive decline in the vigour of basic plants is due to sub-clinical disease (Beddows and Stephens, personal communication). It may well be that cytoplasmic segregation has contributed to this decline. If some of these effects are transmitted over sexual cycles, as suggested by the results of Hayward and Breese (1968), then this may lead to a general decline in the vigour of the commercial variety. Further information on the occurrence and course of somatic variability is therefore germane to the maintenance of the variety whether by seed or plant.

Acknowledgements.-We wish to thank Professor P. T. Thomas, Director, Welsh Plant Breeding Station, and Dr E. L. Breese for their interest and guidance in this work. One of us (Y. S.) wishes to acknowledge the receipt of a grant from the Japanese Ministry of Education.

\section{REFERENCES}

BEAN, E. W. 1972. Clonal evaluation for increased seed production in two species of forage grasses, Festuca arundinacea Schreb and Phleum pratense. Euphytica, 21,377-383.

BREESE, E. L., HAYWARD, M. D., AND THOMAS, A. C. 1965. Somatic selection in perennial ryegrass. Heredity, 20, 367-379.

BURTON, G. W., AND DE VANE, E. H. 1953. Estimating heritability in tall fescue (Festuca arundinacea) from replicated clonal material. Agron. Four., 46, 478-481.

DARLIngton, C. D. 1958. Evolution of Genetic Systems, 2nd Ed. Oliver and Boyd, London. 265 pp.

HAYWARD, M. D., AND BREESE, E. L. 1968. Genetic organization of natural populations of Lolium perenne. (iii) Productivity. Heredity, 23, 357-368.

HAYWARD, M. D., AND KOERPER, F. D. W. 1973. Environmentally induced variability in Lolium perenne. Z. Pflanzenzuchtg, 70, 195-199.

LERNer, I. M. 1958. The Genetic Basis of Selection. John Wiley and Sons, Inc., New York.

LIBBy, w. J., AND JUnd, E. 1962. Variance associated with cloning. Heredity, 17, 533-540.

PALENZONA, D. L., CAVICCHI, s., AND MICARDI, L. 1973. Irreversible phenotypic changes in Phleum associated with cloning in different environments. Proc. International meeting on Quantitative Inheritance, Polymorphisms, Selection and Environment. Bologna, Italy, 1972.

THOMAS, J. R., AND FRAKES, R. v. 1967. Clonal and progeny evaluation in two populations of tall fescue (Festuca arundinacea Schreb.). Crop Science, 7, 55-58.

WILCOX, J. R., AND FARMER, R. E. 1968. Heritability and " $\mathrm{G}$ " effects in early root growth of eastern cotton wood cutting. Heredity, 23, 239-245. 